\title{
Natural Fiber-based Composites with High Hydrophobic, Magnetic, and EMI Shielding Properties via Iron Oxide In Situ Synthesis and Copper Film Deposition
}

\author{
Quanliang Wang, ${ }^{\mathrm{a}}$ Jie Tang, ${ }^{\mathrm{b}}$ Shengling Xiao, ${ }^{\mathrm{a}, *}$ Min Wang, ${ }^{\mathrm{c}, *}$ and Sheldon Q. Shi ${ }^{\mathrm{d}}$ \\ A sandwich-structured natural fiber-based magnetic composite, without \\ the use of a binder, was developed in this study. It was fabricated via in \\ situ synthesis, densification, and magnetron sputtering processes. The \\ chemical composition, crystal structure, microstructure, and thermal \\ stability were characterized via X-ray photoelectron spectroscopy, energy- \\ dispersive spectroscopy, X-ray diffraction, scanning electron microscope, \\ and thermogravimetric analysis. The hydrophobic, magnetic, and \\ electromagnetic interference shielding properties were investigated by \\ measuring the static water contact angle, the magnetic hysteresis loops, \\ and the shielding effectiveness. The resulted composites exhibited a \\ unique inner structure with a larger iron oxide size and content (492 nm \\ and $26.1 \mathrm{wt} \%$ ) on the interlayer surface in comparison to the core layer \\ (135 $\mathrm{nm}$ and $18.7 \mathrm{wt} \%$ ). The magnetic response can be controlled by the \\ loaded iron oxide content and the copper film deposition. Sputtering \\ copper film changed the surface free energy, and created rough micro- \\ /nanostructures, which yielded a highly hydrophobic nature $\left(133^{\circ}\right.$ in water \\ contact angle), and approximately $99.2 \%$ of the electromagnetic energy \\ was shielded by the $0.8 \mathrm{~mm}$ thick composite.
}

Keywords: Natural fiber; Magnetic composites, Sandwich structure; Hydrophobic property; EMI shielding

Contact information: a: College of Engineering and Technology, Northeast Forestry University, Harbin 150040 China; b: Guilin University of Technology AT Nanning, Nanning 530000 China; c: College of Bioresources Chemical and Materials Engineering, Shaanxi University of Science \& Technology, Xi'an 710021, China; d: Department of Mechanical and Energy Engineering, University of North Texas, Denton, TX 76203 USA; *Corresponding authors: shenglingxiao@126.com; wangminunt@126.com

\section{INTRODUCTION}

The rational growth and array design of nanostructures on polymeric matrices are of great importance in terms of constructing multifunctional materials with high performance. Considering the merits of different materials, the design of functional composite materials with excellent constructions, e.g., sandwich structure, are emerging as an effective way to solve the paradox between different properties, such as high breakdown strength and enhanced permittivity (Wang et al. 2017). A sandwich-structured composite, which is composed of an electrically conductive layer and a carbonaceous or polymeric substrate, has potential advantage as an electromagnetic interference (EMI) shielding media by combining the characteristics of conductivity and stable interlayers (Liu et al. 2014). To date, sandwich-structured composites comprising of carbonaceous materials, transition-metal oxides, conducting polymers, etc. have been widely designed $\left(\mathrm{MnO}_{2} / \mathrm{Mn} / \mathrm{MnO}_{2}\right.$ (Li et al. 2012), Graphene-Fe $3 \mathrm{O}_{4} @$ Carbon (Zhao et al. 2015), $\mathrm{Co}_{3} \mathrm{O}_{4} @$ Carbon Fiber@ $\mathrm{Co}_{3} \mathrm{O}_{4}$ (Shi et al. 2018), ZnO/ZnS/Au (Liu et al. 2015c), C/Ge/ Graphene (Li et al. 2013), Nafion/PtRu@ $\mathrm{SiO}_{2} / \mathrm{Nafion}$ (Wu et al. 2013), Pt@ZSM-5 nanosheets (Liu et al. 2019), C@Si@C nanotube array (Liu et al. 2015a), PANI/ 
graphene/PANI (Tong et al. 2014), PVDF@BT/PVDF/BT@PVDF (Wang et al. 2017), $\mathrm{NaYF}_{4} @ \mathrm{NaYF}_{4}: \mathrm{Er}^{3+} / \mathrm{Yb}^{3+} @ \mathrm{NaYF}_{4}$ (Zhang et al. 2018), and PVDF/PMIA/PVDF (Zhai et al. 2014), $\mathrm{PVDF} / \mathrm{BaSrTO}_{3} / \mathrm{TiO}_{2}$ (Hu et al. 2013)) and applied in supercapacitors (Liu et al. 2015b; Choi et al. 2016), lithium batteries (Song et al. 2014a; He et al. 2015), hydrogen storage (Feng et al. 2016; Han et al. 2017), biological detection (Meher and Rao 2013), photocatalysts (Tian et al. 2014), surface-enhanced Raman scattering (Liu et al. 2014), and anisotropic conductive films (Yang et al. 2019) to improve device performance. However, most of these structural materials are confined to nanocomposites or composite membrane materials. For practical applications, these sandwich-structured nanocomposites have to be further processed by mixing in order to form the macroscopic composites. In addition, these materials are usually subjected to high temperature treatment, and thus they have to rely on additional binders during further processing.

The rapid development of technology along with various electronic devices, e.g., communication facilities, wireless networks, and portable digital hardware, has drawn the most concern in terms of electromagnetic pollution. Electromagnetic radiation not only interferes with the operation of electronic devices, but it also causes serious health risks in humans (Song et al. 2014b). Multifunctional materials, such as EMI shielding products, play a more important role in today's society in terms of blocking and attenuating unexpected electromagnetic irradiations (Munaweera et al. 2014; Gan et al. 2017b). In recent years, searching for electromagnetic attenuation materials has become a hot topic. Incorporating conductive fillers into polymeric matrices is considered to be an effective way to fabricate EMI shielding materials, owing to their easy processing and adjustable shielding performances (Wang et al. 2019a). Most of the research focuses on introducing various carbon materials, e.g., graphene, carbon nanotube, carbon nanofiber, and carbon black (Li et al. 2006; Al-Saleh et al. 2013; Lee et al. 2017); metal oxides, e.g., $\mathrm{Fe}_{3} \mathrm{O}_{4}$, $\mathrm{MnO}_{2}$, and $\mathrm{CrO}_{2}$ (Menon et al. 2019; Wang et al. 2019a); and noble metals, e.g., Au nanoparticles and Ag nanowires (Fang et al. 2016; Sun et al. 2018) into polymeric matrices, such as polyurethane (PU) and polyaniline (PANI) (Thomassin et al. 2013; Shen et al. 2016), for high-efficient EMI shielding. These composites comprising of conductive fillers and polymers can achieve the desired EMI shielding performance. However, there still remains some challenges, namely the high cost of electrically conductive fillers, e.g., the widely used graphene and PANI, and the environmental impacts due to petroleum-derived polymer substrates.

Natural fibers for functionalized composites have attracted an increasing amount of attention in the applied fields of biomedicine, electronics, and energy, due to their low cost, lightweight nature, high chemical stability, as well as being environmentally friendly (Gan et al. 2017a). In addition, biomass-derived fibers, e.g., wood fibers, usually have a hollow cell wall structure, which can serve as an efficient substrate for loading conductive active materials in order to improve EMI shielding properties. The existing method for fabricating EMI shielding natural fiber composites is to first introduce electrically conductive materials, such as iron oxide (Ding et al. 2015; Xia et al. 2016b), carbon nanotubes (Tzounis et al. 2014), or powdered activated carbon (Xia et al. 2015), into the natural fibers, and then to use these treated fibers to fabricate the final EMI shielding composites. However, owing to the limited void space in fiber lumina for the filler loading, the EMI shielding function of natural fiber composites is restricted. Moreover, these composites are fabricated with the assistance of additional adhesives, such as phenol formaldehyde and urea formaldehyde. Coating a thin metal film on the surface of the composite can also achieve the EMI shielding. Especially for natural fiber materials, their hydrophilic defects 
can be solved by depositing a hydrophobic metallic film. Compared to other coating substances, copper can be used to form the thin films needed for EMI shielding applications while providing oxidation resistance and acceptable costs (Wu et al. 2018). Meanwhile, magnetron sputtering provides a convenient copper film coating route with a high deposition rate (Kim et al. 2018; Wang et al. 2019b). Researchers have reported that magnetron sputtering a thin copper film onto the surface of natural fiber composites for EMI shielding demonstrated good hydrophobicity from the resulting composite (Xia et al. 2016a; Wang et al. 2019b). However, the heterogeneous interfacial bonding between the biomass substrates and the metallic coatings becomes a challenge when the thin metallic films are directly deposited onto the cellulosic fiber surfaces.

In this work, a novel sandwich-structured natural fiber composite was developed. The magnetic interlayer is comprised of natural fibers and iron oxide particles, while the outer layers are a thin copper film. The iron oxide compounds were first in situ synthesized into a porous natural fiber matrix. The moist fiber matrix/iron oxide complex was then densified via hot pressing. Finally, the densified magnetized fiber matrix was sandwiched between thin copper films via magnetron sputtering. The morphology and compositions were characterized via scanning electron microscopy (SEM), energy-dispersive spectroscopy (EDS), X-ray diffraction (XRD), Fourier transform infrared spectroscopy (FTIR), and X-ray photoelectron spectroscopy (XPS). The hydrophobicity, thermal stability, magnetic function, and EMI shielding properties were investigated via thermogravimetric analysis (TGA), static water contact angle, magnetic hysteresis loop, and EMI shielding effectiveness, respectively.

\section{EXPERIMENTAL}

\section{Materials}

The chemi-thermomechanical pulp fibers from poplar wood were fabricated in the laboratory by reference to our previous work (Wang et al. 2018). All of the following chemicals were purchased from the Sinopharm Chemical Reagent Company (Beijing, China): iron trichloride hexahydrate $\left(\mathrm{FeCl}_{3} \cdot 6 \mathrm{H}_{2} \mathrm{O}\right.$ greater than $98.0 \%$ purity), iron dichloride tetrahydrate $\left(\mathrm{FeCl}_{2} \cdot 4 \mathrm{H}_{2} \mathrm{O}\right.$, greater than $98.0 \%$ purity), hydrochloric acid $(\mathrm{HCl}$ $38.0 \%)$, and ammonium hydroxide solution $\left(\mathrm{NH}_{3} \cdot \mathrm{H}_{2} \mathrm{O} 28.0 \%\right)$.

\section{In situ synthesis and densified treatment for the composite interlayer}

The in situ synthesis of the iron oxide compounds was performed on a natural fiber matrix $\left(0.29 \mathrm{~g} \mathrm{~cm}^{-3}\right)$, which was made of pulp fibers via a mild molding process. A $40 \mathrm{~mm}$ $\times 40 \mathrm{~mm} \times 3.8 \mathrm{~mm}$ fiber matrix was impregnated in an acidic solution containing $\mathrm{FeCl}_{2}$ and $\mathrm{FeCl}_{3}$ at room temperature for $3 \mathrm{~h}$. The mixed solutions $(60 \mathrm{~mL})$ were prepared with different iron ion contents $\left(3.75 \mathrm{E}-3 \mathrm{~mol} \mathrm{Fe}{ }^{3+} / 1.875 \mathrm{E}-3 \mathrm{~mol} \mathrm{Fe}{ }^{2+}, 7.5 \mathrm{E}-3 \mathrm{~mol} \mathrm{Fe}^{3+} / 3.75 \mathrm{E}-3\right.$ mol $\mathrm{Fe}^{2+}$, and $1.5 \mathrm{E}-2 \mathrm{~mol} \mathrm{Fe}{ }^{3+} / 7.5 \mathrm{E}-3 \mathrm{~mol} \mathrm{Fe}{ }^{2+}$ ). Subsequently, the iron ion solutions (containing the fiber mat) were heated at $80{ }^{\circ} \mathrm{C}$ in a water bath, and the $\mathrm{pH}$ value of the reaction solution was adjusted to 9.0 by adding ammonium hydroxide, which was maintained for $1 \mathrm{~h}$ while stirring. According to previous reports (Pang et al. 2010; Chin et al. 2014), the iron oxide compounds were in situ synthesized in the fiber matrix.

The densification of the natural fiber/iron oxide complexes was performed at a high temperature without using any binders. After an ultrasonic wash in distilled water, the magnetized fiber matrices (with a moisture content of $c a .50 \%$ ) were hot pressed at $170{ }^{\circ} \mathrm{C}$ 
and $4 \mathrm{MPa}$ for $20 \mathrm{~min}$. Then the densified magnetized fiber matrices (DM-FM) were obtained. The DM-FM composites (i.e., the interlayer used for the magnetic composites) with an iron oxide loading content from low to high were coded as DM-FM-a, DM-FM-b, and DM-FM-c, respectively. Note that the iron oxide particles and the natural fiber matrices were also separately compressed at $170{ }^{\circ} \mathrm{C}$, and the obtained hot-pressed iron oxide and pristine fiber sheet were used as the control groups.

\section{Thin copper film magnetron sputtering for the sandwich structure}

The sandwich structure was constructed by depositing a thin copper film on the surface of the DM-FMs to instill a highly hydrophobic nature and increase EMI shielding performance. A DLZ-01 plasma-based ion injector (Harbin Institute of Technology, Harbin, China) was used to deposit the thin copper film using a high-purity copper target (99.9\%). A copper target current of $300 \mathrm{~mA}$ was applied during the deposition process. The sputtering vacuum pressure was adjusted to approximately $0.5 \mathrm{~Pa}$ using argon gas with a flux of $30 \mathrm{sccm}$. Prior to the sputtering, each sample was cut to $20 \mathrm{~mm} \times 20 \mathrm{~mm}$. The processing time was set for $1.0 \mathrm{~h}$. The sputtered DM-FM-c specimen was coded as SDMFM-c.

\section{Methods}

The scanning electron microscope (SEM) observations were performed with FEI Quanta-200 microscopy (Hillsboro, OR, USA) equipped with an energy-dispersive spectroscopy (EDS) detector for element analysis. To determine the particle size distributions, ca. 200 metal grains were measured in the obtained SEM images with a $10000 \times$ magnification for each sample. The X-ray photoelectron spectroscope (XPS) analysis was carried out with a Thermo Escalab 250Xi spectrometer (Waltham, MA, USA) equipped with a dual X-ray source using Al-Ka, where the deconvolution of the overlapping peaks was conducted with a mixed Gauss-Lorentz fitting software program (XPSPEAK41, Thermo Fisher Scientific Company, Waltham, MA, USA). The X-ray diffraction (XRD) spectra were recorded with a Rigaku D/max 2200 instrument (Tokyo,

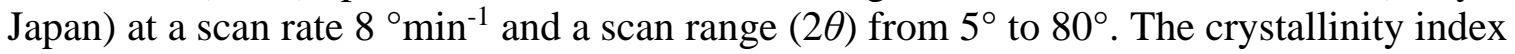
was calculated using the Segal method (Fei et al. 2017). The Fourier transform infrared (FTIR) spectra were recorded with a PerkinElmer Frontier instrument (Waltham, MA, USA) in the range from $4000 \mathrm{~cm}^{-1}$ to $400 \mathrm{~cm}^{-1}$ with a resolution of $4 \mathrm{~cm}^{-1}$. The thermal properties, in terms of thermogravimetric (TG) analysis and its derivative thermogravimetric (DTG) analysis were studied with a TA SDT Q600 simultaneous thermal analyzer (TA Instruments, New Castle, DE) by heating the samples from room temperature to $900{ }^{\circ} \mathrm{C}$ with a heating rate of $20{ }^{\circ} \mathrm{C} / \mathrm{min}$ under a nitrogen flow of 100 $\mathrm{mL} / \mathrm{min}$. The ash content was determined with a YX- HF ash monitor (Xuyu Technology Co., Ltd, Tianjin, China) at $900{ }^{\circ} \mathrm{C}$ for $60 \mathrm{~min}$, according to standard GB/T 742 (2008). Iron oxide only undergoes phase transformation with minimal weight loss under the pyrolysis conditions with a temperature range of $200{ }^{\circ} \mathrm{C}$ to $900{ }^{\circ} \mathrm{C}$ (Pan et al. 2011). Thus, the iron oxide loading content can be evaluated by calculating the residual ash content, with the exception of the natural fibers. The thickness of the thin copper film was measured using a back scattered electron imaging technique with a SEM by observing the sample cross-sections (Zhu et al. 2008).

The hydrophobic properties of the samples were characterized by the static water contact angle at a contact time of $1 \mathrm{~min}$, using an OCA20 contact angle analyzer (Data Physics Co., Regensburg, Germany) at ambient temperature, and five measurements at 
different places were averaged as the water contact angle value. The magnetic properties were measured on a LakeShore 7404 vibrating sample magnetometer (VSM) (Lake Shore Cyrotronics, Westerville, $\mathrm{OH}$ ) at room temperature with an applied field of $-15 \mathrm{kOe}$ to 20 kOe. The EMI shielding effectiveness (SE) measurements were conducted with an Agilent N5244A PNA-X Network Analyzer (Santa Clara, CA, USA). The scattering parameters $\left(\mathrm{S}_{11}\right.$ and $\left.\mathrm{S}_{21}\right)$ in the frequency range of $8.2 \mathrm{GHz}$ to $12.4 \mathrm{GHz}$ were recorded. The total EMI $\mathrm{SE}$ ( $\left.S E_{\text {total }}\right)$, absorption shielding $\left(S E_{\mathrm{A}}\right)$, and reflection shielding $\left(S E_{\mathrm{R}}\right)$ were obtained using Eq. 1, Eq 2., and Eq 3. The $S E_{\text {total }}$ can be expressed as Eq. 1,

$$
S E_{\text {total }}(\mathrm{dB})=10 \lg \left(P_{1} / P_{2}\right)=20 \lg \left(E_{1} / E_{2}\right)=S E_{\mathrm{A}}+S E_{\mathrm{R}}+S E_{\mathrm{M}}
$$

where $P_{1}\left(E_{1}\right)$ and $P_{2}\left(E_{2}\right)$ are the power (electric field) of incident and the transmitted electromagnetic wave, respectively (Wan and $\mathrm{Li}$ 2016). $S E_{\mathrm{A}}, S E_{\mathrm{R}}$, and $S E_{\mathrm{M}}$ are the shielding effectiveness due to absorption, reflection, and multiple internal reflection, respectively (Wan and Li 2016). Usually, the $S E_{\mathrm{M}}$ can be ignored when the $S E_{\text {total }}$ is higher than $10 \mathrm{~dB}$ (Bora et al. 2016). In addition, $S E_{\mathrm{R}}$ and $S E_{\mathrm{A}}$ can be described by Eqs. 2 and 3,

$$
\begin{aligned}
& S E_{\mathrm{R}}=-10 \lg (1-R) \\
& S E_{\mathrm{A}}=-10 \lg (T /(1-R))
\end{aligned}
$$

where the reflected power $(R)$ and transmitted power $(T)$ can be derived from the scattering parameters ( $S_{\mathrm{ij}}$ denotes the power transmitted from port i to port $\mathrm{j}$ ), viz., $R=\left|S_{11}\right|^{2}=\left|S_{22}\right|^{2}$, $T=\left|S_{12}\right|^{2}=\left|S_{21}\right|^{2}$ (Bi et al. 2017). The absorbed power $(A)$ is calculated from the reflected and transmitted power, viz., $A=1-R-T$. There are several factors that can affect the EMI shielding effectiveness, e.g., conductivity, complex permeability, and complex permittivity (Bora et al. 2016).

\section{RESULTS AND DISCUSSION}

\section{Preparation Process of Natural Fiber-Based Magnetic Composites}

The sandwich-structured magnetic composites were developed via a three-step procedure including in situ synthesis of iron oxide compounds, densification of the fiber/iron oxide complex, and copper film magnetron sputtering (as shown in Fig. 1). The densified composite interlayer was sandwiched between thin copper films to form the final magnetic composites.

As shown in Fig. 1, the composite interlayers were fabricated from a porous natural fiber mat. During the in situ synthesis process, the ammonia penetrated the fiber mat surface into its interior, which formed an ammonia concentration gradient. Thus, the iron oxide was unevenly grown and distributed in the fiber mat. In order to improve the interlayer strength, the fiber/iron oxide complex ( $\mathrm{ca}$. 50\% moisture content) was densified via hot pressing, which could also enable the immobilization of the iron oxide compounds within the fiber mat. It is worth noting that the in situ method can allow for a higher iron oxide loading content due to the larger pore spaces in the fiber mat.

The outer layers of the composites were constructed via magnetron sputtering copper film on the surfaces. Owing to the gradient iron oxide distribution, the nano-sized iron oxide particles were beneficial to the internal bonding strength, and the formed surface metallic texture could also be conducive to the copper film deposition. 


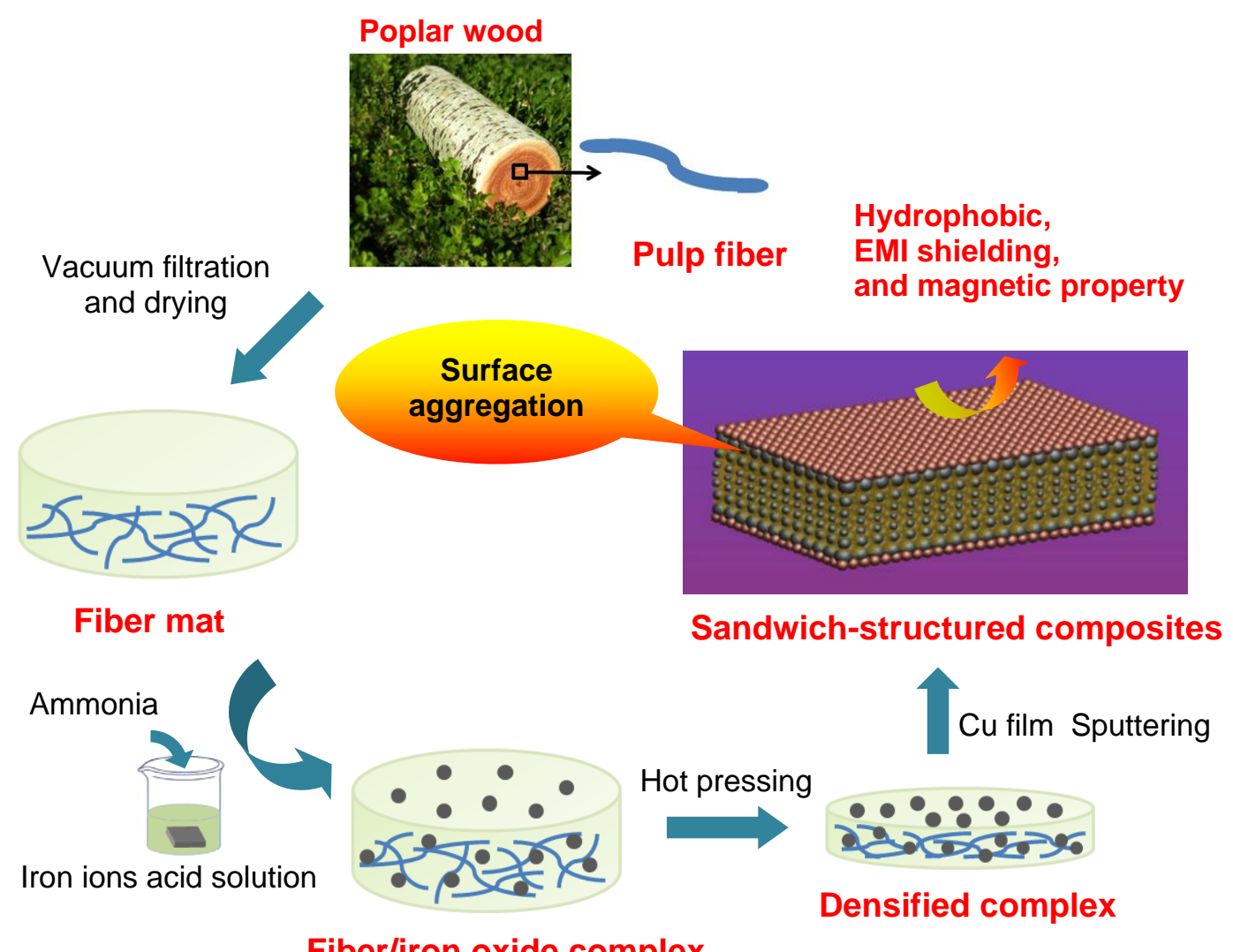

Fiber/iron oxide complex

Fig. 1. Schematic to illustrate the fabrication processes for the natural fiber-based magnetic composites

\section{Characterizations via SEM, EDS, XRD, FTIR, and XPS}

The microstructures and element components of the magnetic composites were investigated via SEM observations and EDS analysis, respectively (as shown in Fig. 2). As shown in Fig. 2a and Fig. 2e, the pristine fiber sheet showed a smooth surface without any heterogeneous particles. These fibers were well intertwined and bonded. Figures $2 b, 2 f$, and $2 \mathrm{~m}$ exhibit the inner morphology of the magnetic composites, where the iron oxide nanoparticles, with uniform sizes ( $c a .135 \mathrm{~nm}$ in diameter), were densely bonded and arrayed onto the surface of the fibers. The porous fiber mat allowed for the full penetration of the iron ions into the inter-fiber pores, which facilitated the formation of iron oxide nanoparticles in situ within the fiber mat. Figures $2 \mathrm{c}, 2 \mathrm{~g}$, and $2 \mathrm{n}$ show the interlayer surface of the magnetic composites, where the larger-sized iron oxide particles (492 $\mathrm{nm}$ in diameter) were formed on the surface. This could be attributed to the inhomogeneous growth and array of iron oxide compounds in the natural fiber matrix during the in situ synthesis and hot pressing processes; thus, a hierarchical structure was constructed in the interlayer. Notably, the enrichment of iron oxide not only serves as a protective layer for the cellulosic substrate, but also provides enough metallic sites for structural interlocking with the sputtered thin copper film. The rough metallic surface comprising of oxide particles and micro-sized fiber network provided a platform for copper atoms penetration and the corresponding film attachment. Figures $2 \mathrm{~d}, 2 \mathrm{~h}$, and $2 \mathrm{o}$ show the outer layer of the magnetic composites. As expected, the nano-sized spherical copper grains (497 $\mathrm{nm}$ in diameter) were densely deposited on the iron oxide loaded fiber surface, and a highly metallic texture was formed on the surface of the composites. 


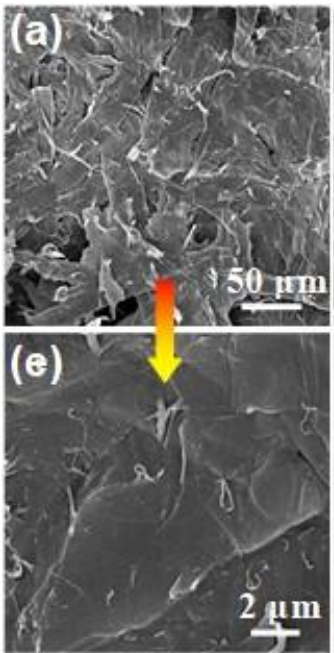

(i)

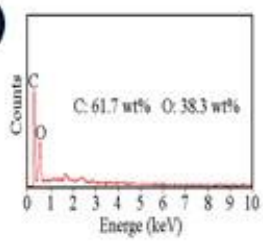

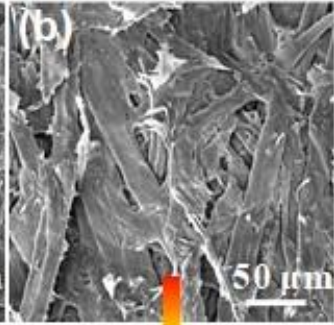
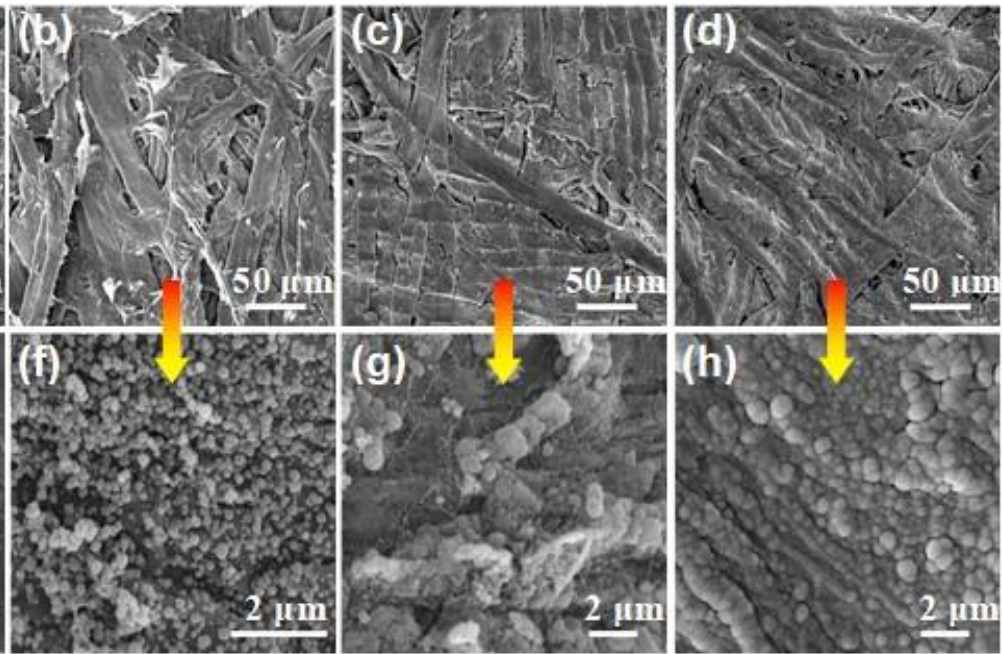

(j)

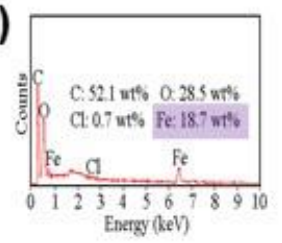

(k)

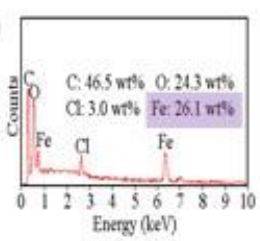

(I)

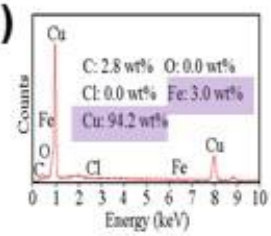

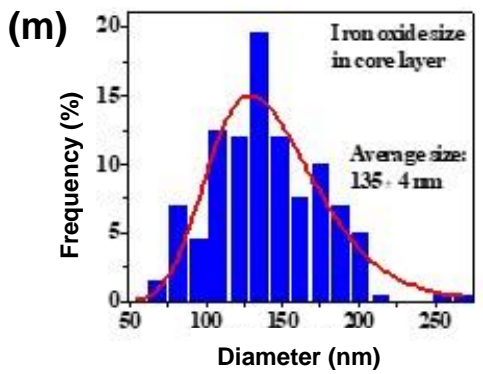
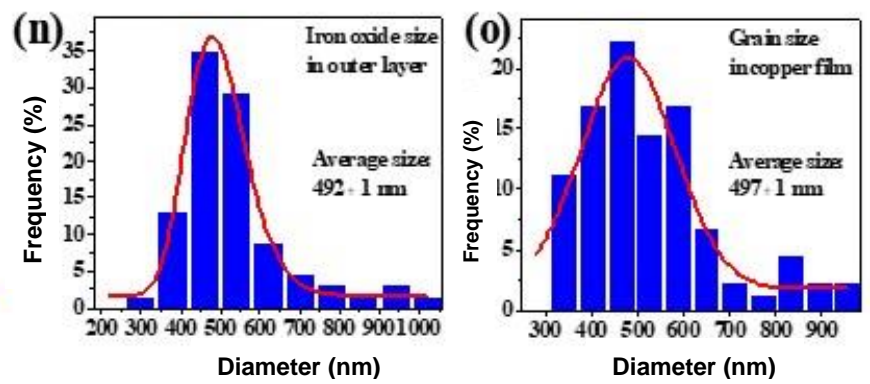

Fig. 2. SEM images of the core layers (a: pristine fiber sheet; b: DM-FM-c) and the outer layers (c: DM-FM-C; d: SDM-FM-C), and their corresponding high-resolution SEM images are presented in (e), (f), (g), and (h), respectively. The EDS spectra of the core layers (i: pristine fiber sheet; j: DMFM-c) and the outer layers (k: DM-FM-c; l: SDM-FM-c). The statistical grain size distributions of iron oxide are shown (a: core layer of DM-FM-c; b outer layer of DM-FM-c) and thin copper film (c: outer layer of SDM-FM-C).

The pristine fiber sheet was primarily composed of $\mathrm{C}$ and $\mathrm{O}$ elements, determined by the EDS analysis (Fig. 2i). After the in situ synthesis of the iron oxide compounds, strong Fe peaks appeared at $0.73 \mathrm{keV}$ and $6.41 \mathrm{keV}$, (Fig. 2j), which indicated the successful introduction of iron oxide into the fiber mat, which also resulted in the $\mathrm{O} / \mathrm{C}$ value decreasing from 0.62 to 0.55 . Importantly, from the core layer to the outer layer of the magnetic composites (as shown in Fig. $2 \mathrm{j}$ and Fig. 2k), the Fe content increased from $18.7 \mathrm{wt} \%$ to $26.1 \mathrm{wt} \%$, and the $\mathrm{O} / \mathrm{C}$ value decreased from 0.55 to 0.52 , which demonstrated the gradient distribution of the iron oxide compounds in the interlayer, and was in good agreement with the SEM observation results. Thus, the hierarchical structure of the composite interlayer was further demonstrated. After sputtering the thin copper film, strong copper peaks appeared at $0.96 \mathrm{keV}$ and $7.96 \mathrm{keV}$ (Fig. 21), and the copper content was as high as $94.2 \mathrm{wt} \%$. Except for the pristine fiber sheet, a weak $\mathrm{Cl}$ peak was detected in other 
samples, which was owed to the hydrochloric treatment that was part of the synthesis process.

The crystal structures of the magnetic composites were analyzed via XRD (Fig. 3). The pristine fiber sheet revealed a typical cellulose I crystal structure with a main diffraction peak at $22.5^{\circ}$ (002 lattice plane) and a shoulder in the region from $14^{\circ}$ to $17^{\circ}$ (Mmed et al. 2010; Sonia and Dasan 2013). The hot-pressed iron oxide (170 $\left.{ }^{\circ} \mathrm{C}\right)$ exhibited six peaks at $30.3^{\circ}, 35.7^{\circ}, 43.0^{\circ}, 53.8^{\circ}, 57.2^{\circ}$, and $62.8^{\circ}$, corresponding to the (220), (311), (400), (422), (511), and (440) planes of the $\gamma-\mathrm{Fe}_{2} \mathrm{O}_{3}$ crystal structure (JCPDS card no. 391246), respectively (Pan et al. 2011). The XRD pattern of the magnetic composites verified the co-existence of $\gamma-\mathrm{Fe}_{2} \mathrm{O}_{3}$ and cellulose I crystals. The crystallinity index decreased from $68.4 \%$ (the pristine fiber sheet) to $41.3 \%$ (the magnetic composites), which could be related to the hydrochloric acid treatment during the synthesis process. Three peaks at $43.4^{\circ}, 50.5^{\circ}$, and $74.3^{\circ}$, which corresponded to the (111), (200) and (220) planes of copper (JCPDS card no. 04-0836), were observed for the sputtered composites, which indicated that the thin copper film was deposited onto the composite interlayer surface (Wiatrowski et al. 2011).

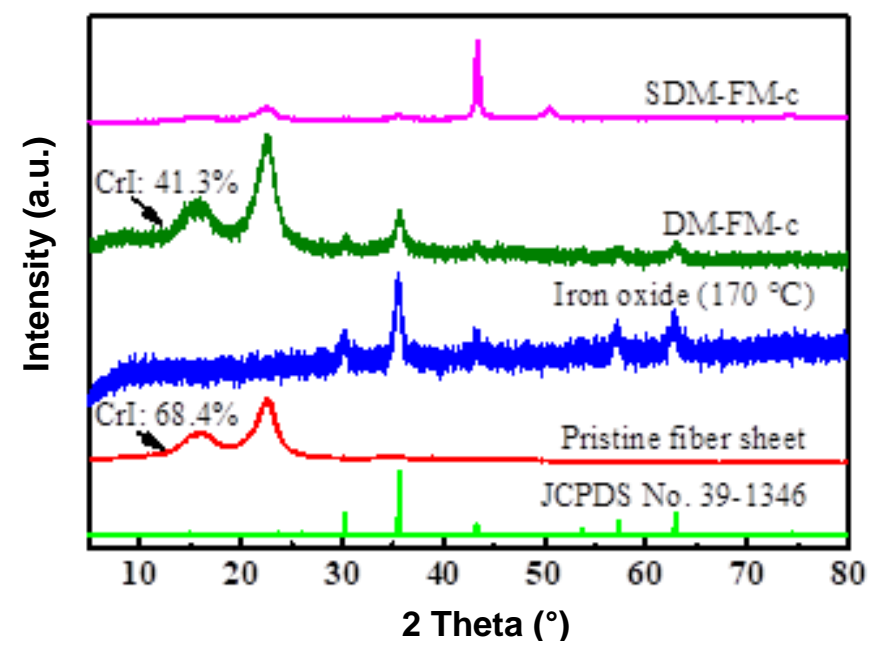

Fig. 3. The XRD patterns of magnetic composites (The bottom line is the standard JCPDS card No. $39-1346$ for $\mathrm{y}-\mathrm{Fe}_{2} \mathrm{O}_{3}$ )

The chemical compositions of the magnetic composites were analyzed via FTIR and XPS (Fig. 4). As shown in Fig. 4a, the absorption band at $579 \mathrm{~cm}^{-1}$ was assigned to the $\mathrm{Fe}-\mathrm{O}$ vibrations in the iron oxide compounds (Qian et al. 2009). After the insertion of iron oxide, there was an enhanced absorption peak centered at $579 \mathrm{~cm}^{-1}$ found in the magnetic composites. Moreover, the decreased absorption intensities at approximately $1034 \mathrm{~cm}^{-1}$, $1373 \mathrm{~cm}^{-1}$, and $1425 \mathrm{~cm}^{-1}$ corresponded to the $\mathrm{C}-\mathrm{O}, \mathrm{C}-\mathrm{H}$, and $\mathrm{CH}_{2}$ groups of cellulose, respectively (Belouadah et al. 2015). This also indicated a transformation of the cellulosic material into a metallic texture during the synthesis and sputtering processes. The absorption bands at approximately $1638 \mathrm{~cm}^{-1}$ and $3430 \mathrm{~cm}^{-1}$ were assigned to the vibrations of water molecules (Ramandi et al. 2017). The absorption peaks at $1732 \mathrm{~cm}^{-1}$ and $2885 \mathrm{~cm}^{-}$ 1 , i.e., the characteristics of unconjugated $\mathrm{CO}$ groups and symmetrical $\mathrm{CH}$ groups in hemicelluloses, showed a decreased intensity, which indicated that the hemicelluloses were partly degraded during the in situ process (Mulinari et al. 2016). 
(a)

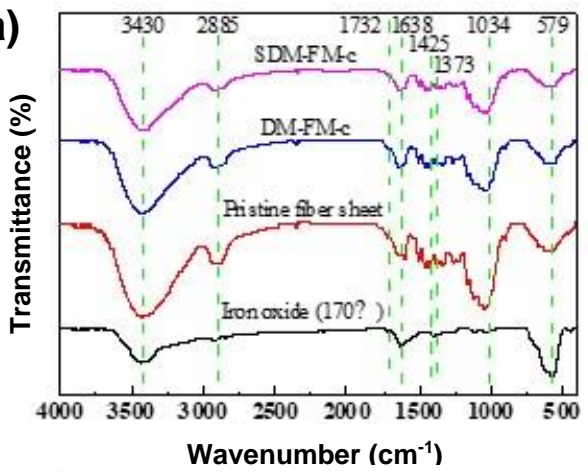

(c)

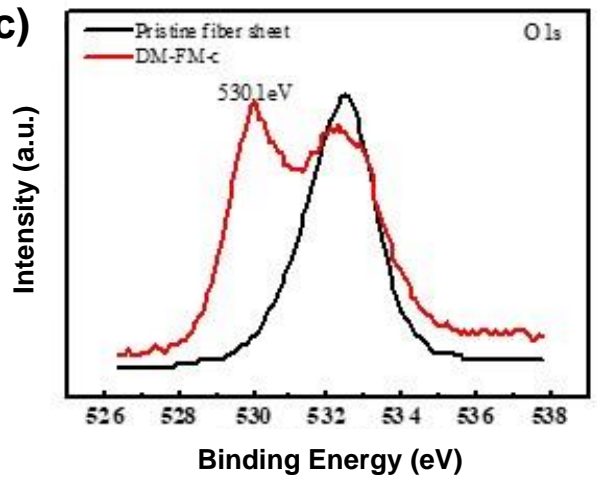

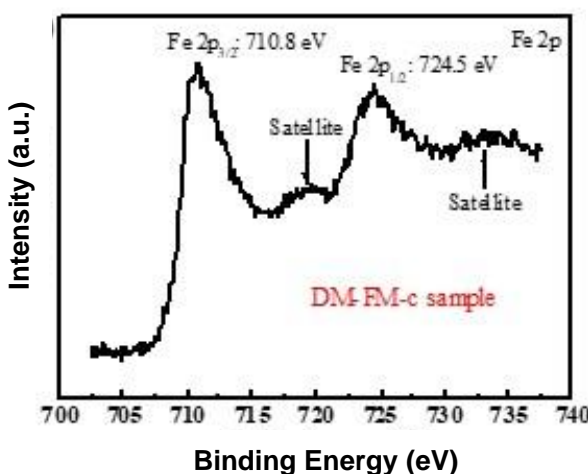

(b)

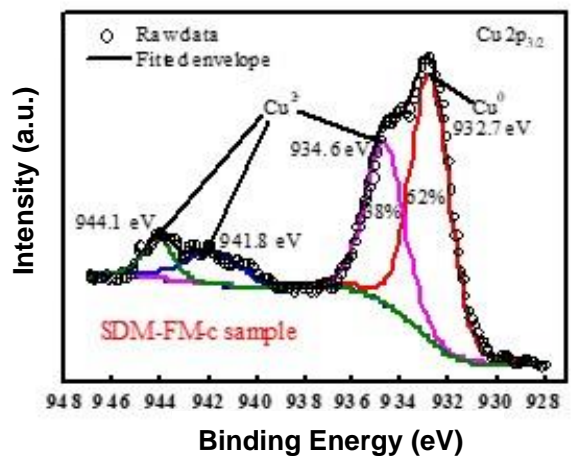

(d)

Fig. 4. The FTIR spectra (a) and high-resolution XPS spectra of (b) Fe 2p, (c) O 1s, and (d) Cu $2 p_{3 / 2}$ for magnetic composites.

To further clarify the compositions of the iron oxide compounds and copper film, the high-resolution XPS spectra of Fe 2p, O 1s, and Cu 2p $3 / 2$ were measured (Figs. 4b, 4c, and 4d). As shown in Fig. 4b, two peaks at $710.8 \mathrm{eV}$ and $724.5 \mathrm{eV}$ were assigned to the Fe $2 \mathrm{p}_{3 / 2}$ and $\mathrm{Fe} 2 \mathrm{p}_{1 / 2}$ electron binding energies, respectively. Two satellite peaks were observed on both sides of the Fe 2 $\mathrm{p}_{1 / 2}$ peak. These satellite structures are characteristic for $\mathrm{Fe}^{3+}$ and indicate the absence of $\mathrm{Fe}^{2+}$ (Zhang et al. 2011; Wu and Wang 2014). Interestingly, a new split peak appeared at $530.1 \mathrm{eV}$ (Fig. 4c), which was assigned to the oxygen atom that was bound to the iron atoms (Fe-O) ( $\mathrm{Li}$ et al. 2016). These results confirmed the presence of $\gamma-\mathrm{Fe}_{2} \mathrm{O}_{3}$ in the magnetic composites.

The peak fitting results of $\mathrm{Cu} 2 \mathrm{p}_{3 / 2}$ are shown in Fig. 4d to study the copper states in the film. The main $\mathrm{Cu} 2 \mathrm{p}_{3 / 2}$ peak at $932.7 \mathrm{eV}$ represented the $\mathrm{Cu}^{0}$ in $\mathrm{Cu}$ metal, while the minor $\mathrm{Cu} 2 \mathrm{p}_{3 / 2}$ peak at $934.6 \mathrm{eV}$ (along with two satellite peaks at $941.8 \mathrm{eV}$ and $944.1 \mathrm{eV}$ ) were assigned to the $\mathrm{Cu}^{2+}$ state in $\mathrm{CuO}$, as reported by Meng et al. (2016), Nourbakhsh et al. (2016), and Liu et al. (2017). Compared with the $\mathrm{Cu}^{2+}$ content (38\%), a higher $\mathrm{Cu}^{0}$ content $(62 \%)$ was obtained through calculation of the peak area, which indicated that most of the surface copper atoms are metallic.

\section{Hydrophobicity, Thermal Stability, Magnetic Responsivity, and EMI Shielding Performance}

The sample dimensions and iron oxide content of the natural fiber-based magnetic composites are listed in Table 1. The fiber mat showed a reduction in thickness of approximately $73 \%$, and correspondingly showed a 3.8-fold increase in density after a hotpressing treatment. This resulted in the magnetic composites having a thickness of $c a .0 .8$ $\mathrm{mm}$. The iron oxide loading content ranged from $4.0 \%$ to $11.2 \%$ by increasing the iron ion 
concentration during the in situ process. The sputtered copper thin film showed a thickness of approximately $1.7 \mu \mathrm{m}$.

Table 1. Sample Dimensions and Iron Oxide Loading Contents

\begin{tabular}{|c|c|c|c|c|}
\hline Samples & $\begin{array}{c}\text { Thickness } \\
(\mathrm{mm})\end{array}$ & $\begin{array}{c}\text { Density } \\
\left(\mathrm{g} \mathrm{cm}^{-3}\right)\end{array}$ & $\begin{array}{c}\text { Iron Oxide Content } \\
(\%)\end{array}$ & $\begin{array}{c}\text { Copper Film } \\
\text { Thickness } \\
(\mu \mathrm{m})\end{array}$ \\
\hline Fiber mat & 3.0 & 0.29 & - & - \\
\hline DM-FM-a & 0.8 & 1.05 & 4.0 & - \\
\hline DM-FM-b & 0.8 & 1.08 & 6.2 & - \\
\hline DM-FM-c & 0.8 & 1.09 & 11.2 & 1.7 \\
\hline SDM-FM-c & 0.8 & 1.10 & 11.2 & - \\
\hline
\end{tabular}

The hydrophobic properties and surface conductivity are presented in Fig. 5. The pristine fiber sheet showed a water contact angle of $c a .77^{\circ}$. When the thin copper film was depositing onto the composite fiber/iron oxide interlayer, the water contact angle was increased to approximately $133^{\circ}$ (Fig. 5b), which indicated that the surface wettability changed from hydrophilic to hydrophobic. The deposition of the copper atoms was continuous on the composite interlayer surface, which could be confirmed by testing the surface conductivity (Fig. 5c). The formation of nano-sized copper grain papillae ( $\mathrm{ca} .500$ $\mathrm{nm})$ on top of micropapillae $(10 \mu \mathrm{m}$ to $18 \mu \mathrm{m})$ formed by the interwoven fibers could be one reason for the increase in hydrophobicity. In addition, the decrease in the surface free energy, i.e., $50 \mathrm{~mJ} \mathrm{~m}^{-2}$ for the cellulosic substrates and $18 \mathrm{~mJ} \mathrm{~m}^{-2}$ for the copper film, could also contribute to the improvement of hydrophobic property (Mohammed-Ziegler et al. 2004; Khan et al. 2017).

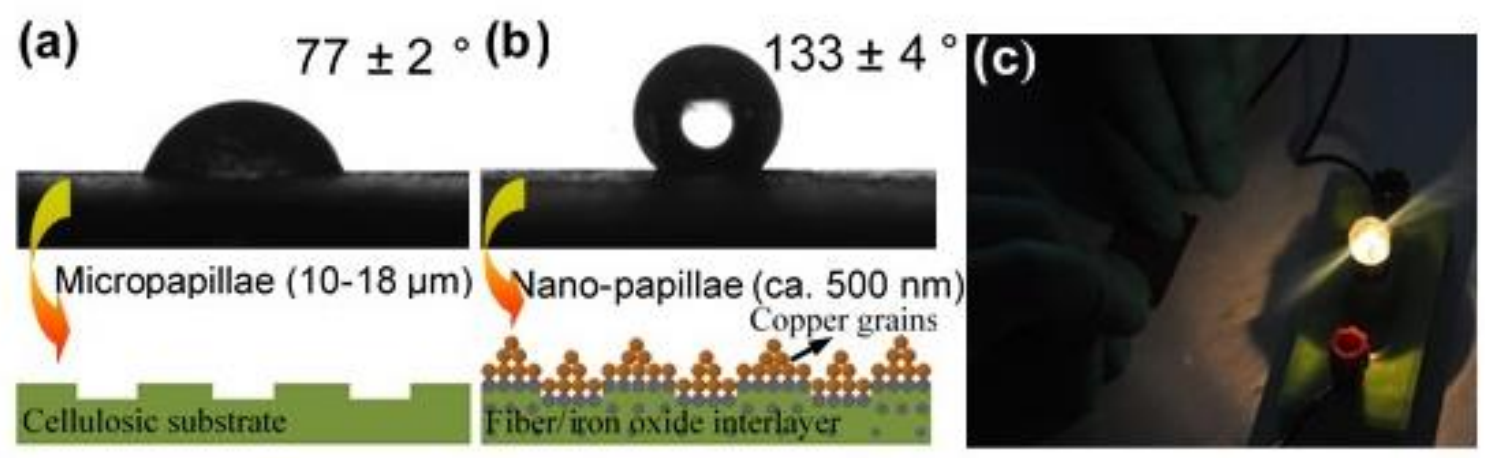

Fig. 5. The water contact angles of (a) pristine fiber sheet and (b) magnetic composites and the surface conductivity of magnetic composites (c)

The thermal stability was studied via TGA (Fig. 6). It could be seen that the pristine fiber sheet started to degrade at $226^{\circ} \mathrm{C}$ due to the degradation of the hemicelluloses and presented a major degradation peak at $384{ }^{\circ} \mathrm{C}$ due to the cellulose depolymerization (Wang et al. 2018). However, the initial thermal degradation of the magnetic composites shifted to a lower temperature $\left(187{ }^{\circ} \mathrm{C}\right)$ with a maximum degradation rate at $360{ }^{\circ} \mathrm{C}$. It demonstrated a slight reduction in thermal stability after the in situ and hot pressing processes, which was consistent with the results of the FTIR and XRD analyses, i.e., the partly-degraded hemicelluloses and decreased crystallinity. Besides that, the formed iron oxide compounds might exhibit a catalytic effect on the thermal decomposition (Lan et al. 
2015). It was noted that the magnetic composites showed a lower weight loss $(61.7 \%)$ compared to the pristine fiber sheet $(84.8 \%)$ at temperature ranges of $180{ }^{\circ} \mathrm{C}$ to $450{ }^{\circ} \mathrm{C}$. The magnetic composites also remained at a higher residual ash weight than the pristine fiber sheet at $880{ }^{\circ} \mathrm{C}$. Interestingly, a DTG peak emerged at ca. $610{ }^{\circ} \mathrm{C}$ for the magnetic composites, which could be attributed to the phase transition from $\gamma-\mathrm{Fe}_{2} \mathrm{O}_{3}$ into $\alpha-\mathrm{Fe}_{2} \mathrm{O}_{3}$ (Pan et al. 2011; Piraman et al. 2016).

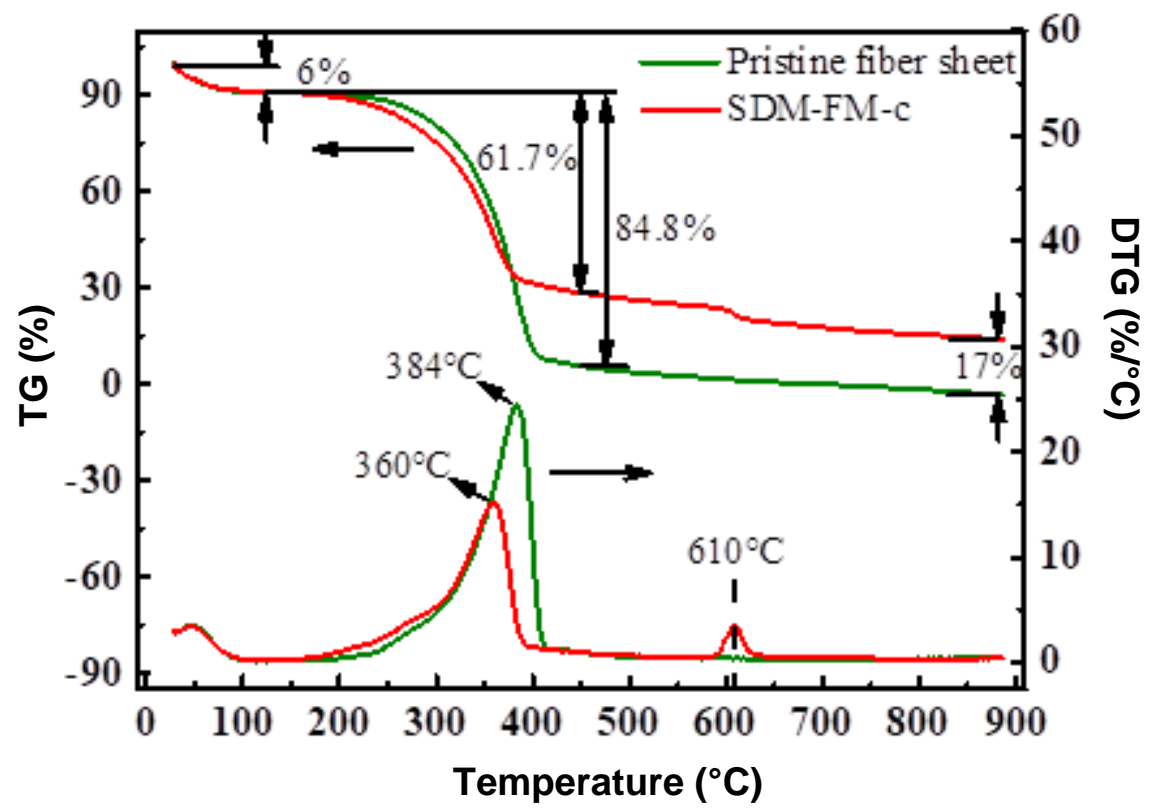

Fig. 6. TG and DTG spectra of the magnetic composites

The magnetic responsivity was evaluated by measuring the magnetic hysteresis loops (Fig. 7a). As shown in Fig. 7a, except for the pristine fiber sheet, all the magnetic composites showed that the coercivity and remanence were close to zero in the magnetization curves, which definitely demonstrated ferromagnetic properties (Ramandi et al. 2017). The saturation magnetization $\left(M_{\mathrm{s}}\right)$ was increased, from 1.5 to $4.4 \mathrm{emu} / \mathrm{g}$, with the iron oxide loading content increasing from $4.0 \%$ to $11.2 \%$ (as shown in Table 1), which indicated that a stronger magnetic response could be achieved by increasing the iron oxide loading amount. Interestingly, the saturation magnetization was further increased to 5.7 $\mathrm{emu} / \mathrm{g}$ after sputtering copper film onto the fiber/iron oxide complex, which could be attributed to the increased specimen thickness after coating and the changes in the ferromagnet lattice constant after the copper doped (Jain et al. 2018). This was not surprising since similar magnetization changes had also been reported for copper doped alloy films (Khan et al. 2016). 
(a)
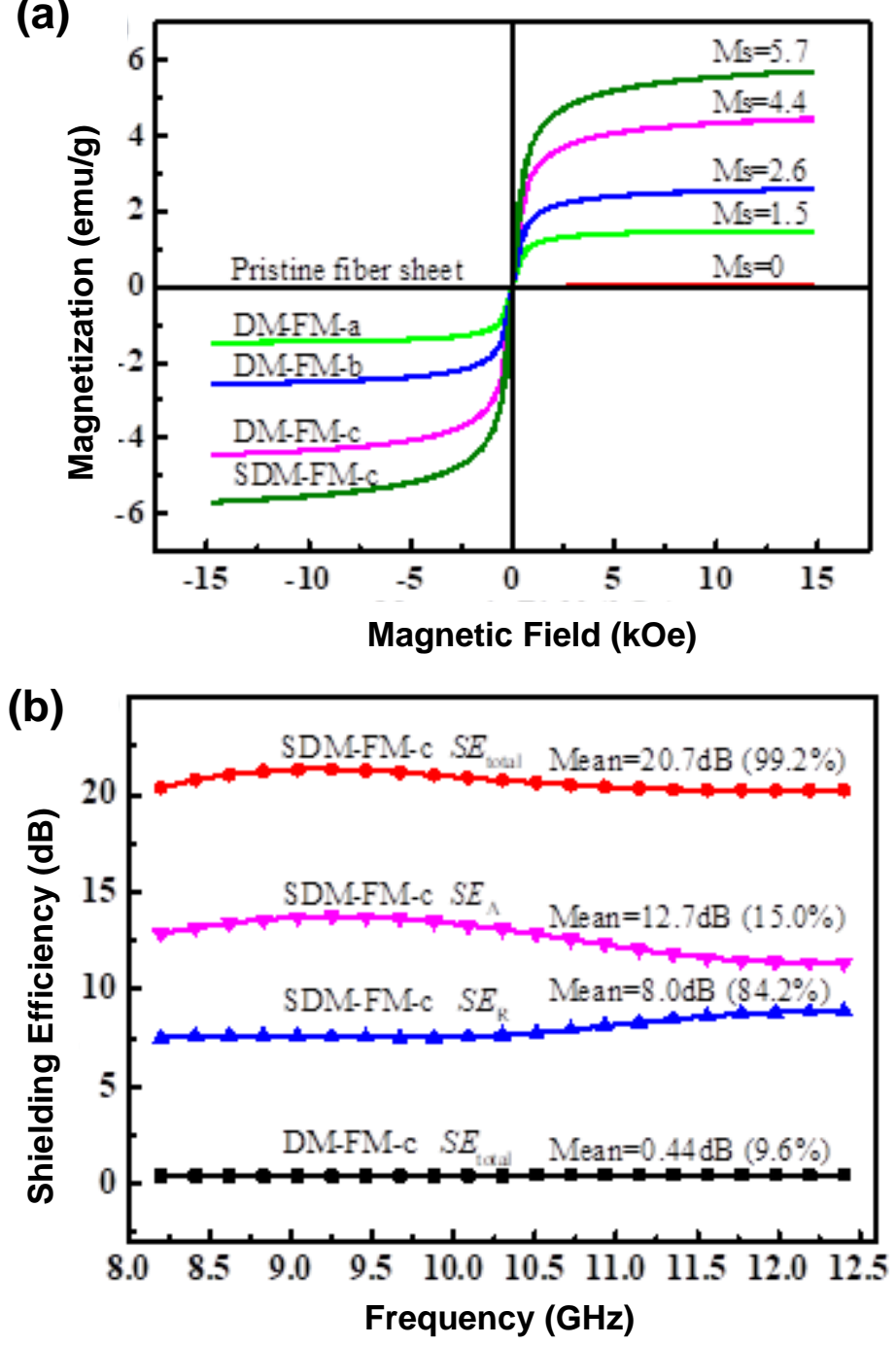

Fig. 7. Vibrating sample magnetometer spectra (a) and EMI shielding effectiveness of the magnetic composites (b)

The EMI shielding performance was analyzed by determining the shielding effectiveness (SE) (Fig. 7b). As shown in Fig. 7b, after sputtering the copper films, the EMI SE increased from 0.44 to $20.7 \mathrm{~dB}$, which indicated that approximately $99.2 \%$ of electromagnetic energy was effectively shielded by the magnetic composites. The EMI shielding mechanism was studied by comparing the contributions of the reflected and absorbed powers to the incident power. Compared to a $15.0 \%$ power loss due to absorption, up to $84.2 \%$ of the incident power was attenuated by reflection, which demonstrated that the EMI shielding of the magnetic composites was wave-reflection dominant ( $\mathrm{Lv}$ et al. 2016; Zhao et al. 2016). This could be attributed to the sputtered thin copper film with a high complex permittivity and a low complex permeability (Qiang et al. 2015; Bera et al. 2017; Liu et al. 2018). Thus the developed composites could have enormous potential in electronic and building applications, such as circuit/coating constructions. 


\section{CONCLUSIONS}

1. A novel natural fiber-based magnetic composite with a sandwich structure was developed in this work. It is comprised of a composite interlayer containing natural fibers and iron oxide, and two outer layers deposited with a thin copper film. The iron oxide loading content was controllable and could be as high as $11.2 \%$. This high loading content was contributed to the abundant pore structures in the fiber matrix, which allowed for greater iron oxide loading amounts.

2. The magnetic composites exhibited a gradient interlayer with a smaller iron oxide particle size of $c a .135 \mathrm{~nm}$ and a total iron oxide content of $18.7 \mathrm{wt} . \%$ for the core layer, and an iron oxide particle size of $c a .492 \mathrm{~nm}$ in size and a total iron oxide content of 26.1 wt.\% for the interlayer surface, which also constructed a metallic texture and supported the thin copper film magnetron sputtering.

3. The formed sandwich structure demonstrated a positive effect on improving the targeted properties. The resulting composites exhibited good thermal stability (maximum degradation rate at $360^{\circ} \mathrm{C}$ ), surface hydrophobic property (water contact angle of $133^{\circ}$ ), magnetic responsivity (saturation magnetization of $5.7 \mathrm{emu} / \mathrm{g}$ ), and electromagnetic interference shielding performance $(99.2 \%$ of the electromagnetic energy was shielded with a thickness of $0.8 \mathrm{~mm}$ ).

\section{ACKNOWLEDGMENTS}

This work was supported by the National Key R\&D Program of China (grant no. 2017YFD0601004) and the Applied Technology Research and Development Project of Harbin (grant no. 2016RAXX J004).

\section{REFERENCES CITED}

Al-Saleh, M. H., Saadeh, W. H., and Sundararaj, U. (2013). "EMI shielding effectiveness of carbon based nanostructured polymeric materials: A comparative study," Carbon 60, 146-156. DOI: 10.1016/j.carbon.2013.04.008

Belouadah, Z., Ati, A., and Rokbi, M. (2015). "Characterization of new natural cellulosic fiber from Lygeum spartum L," Carbohydrate Polymers 134, 429-437. DOI: 10.1016/j.carbpol.2015.08.024

Bera, R., Das, A. K., Maitra, A., Paria, S., Karan, S. K., and Khatua, B. B. (2017). "Salt leached viable porous $\mathrm{Fe}_{3} \mathrm{O}_{4}$ decorated polyaniline - SWCNH/PVDF composite spectacles as an admirable electromagnetic shielding efficiency in extended Ku-band region," Composites Part B: Engineering 129, 210-220. DOI: 10.1016/j.compositesb.2017.07.073

Bi, S., Zhang, L., Mu, C., Liu, M., and Hu, X. (2017). "Electromagnetic interference shielding properties and mechanisms of chemically reduced graphene aerogels," Applied Surface Science 412, 529-536. DOI: 10.1016/j.apsusc.2017.03.293

Bora, P. J., Mallik, N., Ramamurthy, P. C., Kishore, and Madras, G. (2016). "Poly(vinyl butyral)-polyaniline-magnetically functionalized fly ash cenosphere composite film for electromagnetic interference shielding," Composites Part B: Engineering 106, 224-233. DOI: 10.1016/j.compositesb.2016.09.035 
Chin, S. F., Romainor, A. N. B., and Pang, S. C. (2014). "Fabrication of hydrophobic and magnetic cellulose aerogel with high oil absorption capacity," Materials Letters 115(2), 241-243. DOI: 10.1016/j.matlet.2013.10.061

Choi, C., Lee, J. M., Kim, S. H., Kim, S. J., Di, J., and Baughman, R. H. (2016). "Twistable and stretchable sandwich structured fiber for wearable sensors and supercapacitors," Nano Letters 16(12), 7677-7684. DOI: 10.1021/acs.nanolett.6b03739

Ding, Z., Shi, S. Q., Zhang, H., and Cai, L. (2015). "Electromagnetic shielding properties of iron oxide impregnated kenaf bast fiberboard," Composites Part B: Engineering 78, 266-271. DOI: 10.1016/j.compositesb.2015.03.044

Fang, F., Li, Y.-Q., Xiao, H.-M., Hu, N., and Fu, S.-Y. (2016). "Layer-structured silver nanowire/polyaniline composite film as a high performance X-band EMI shielding material," Journal of Materials Chemistry C 4(19), 4193-4203. DOI: 10.1039/C5TC04406E

Fei, M.-E., Xie, T., Liu, W., Chen, H., and Qiu, R. (2017). "Erratum to: Surface grafting of bamboo fibers with 1,2-epoxy-4-vinylcyclohexane for reinforcing unsaturated polyester," Cellulose 24(7-8), 5515-5516. DOI: 10.1007/s10570-017-1534-0

Feng, X., Chen, Y., Qin, Z., Wang, M., and Guo, L. (2016). "Facile fabrication of sandwich structured $\mathrm{WO}_{3}$ nanoplate arrays for efficient photoelectrochemical water splitting," ACS Applied Material Interfaces 8(28), 18089-18096. DOI: 10.1021/acsami.6b04887

Gan, W., Gao, L., Xiao, S., Zhang, W., Zhan, X., and Li, J. (2017a). “Transparent magnetic wood composites based on immobilizing $\mathrm{Fe}_{3} \mathrm{O}_{4}$ nanoparticles into a delignified wood template," Journal of Materials Science 52(6), 3321-3329. DOI: 10.1007/s10853-016-0619-8

Gan, W., Liu, Y., Gao, L., Zhan, X., and Li, J. (2017b). "Magnetic property, thermal stability, UV-resistance, and moisture absorption behavior of magnetic wood composites," Polymer Composites 38(8), 1646-1654. DOI: 10.1002/pc.23733

GB/T 742 (2008). "Fibrous raw material, pulp, paper and board - Determination of ash," Standardization Administration of China, Beijing, China.

Han, L., Qin, W., Jian, J., Liu, J., Wu, X., Gao, P., Hultman, B., and Wu, G. (2017). "Enhanced hydrogen storage in sandwich-structured $\mathrm{rGO} / \mathrm{Co} 1-\mathrm{x} / \mathrm{rGO}$ hybrid papers through hydrogen spillover," Journal of Power Sources 358, 93-100. DOI: 10.1016/j.jpowsour.2017.05.026

He, D., Bai, F., Li, L., Shen, L., Kung, H. H., and Bao, N. (2015). "Fabrication of sandwich-structured Si nanoparticles-graphene nanocomposites for high-performance lithium-ion batteries," Electrochimica Acta 169, 409-415. DOI:

10.1016/j.electacta.2015.04.090

Hu, P., Wang, J., Shen, Y., Guan, Y., Lin, Y., and Nan, C.-W. (2013). "Highly enhanced energy density induced by hetero-interface in sandwich-structured polymer nanocomposites," Journal of Materials Chemistry A 1(39), 12321-12326. DOI: 10.1039/c3ta11886j

Jain, S., Papusoi, C., Admana, R., Yuan, H., and Acharya, R. (2018). "Magnetization reversal process and evaluation of thermal stability factor in $\mathrm{Cu}$ doped granular $\mathrm{L} 10$ FePt films," Journal of Applied Physics 123(19), 193902. DOI: 10.1063/1.5021265

Khan, S. A., Ziya, A. B., Ibrahim, A., Atiq, S., Usman, M., Ahmad, N., and Shakeel, M. (2016). "Enhancement of Curie temperature $(T c)$ and magnetization of Fe-Ni invar 
alloy through $\mathrm{Cu}$ substitution and with $\mathrm{He}^{+2}$ ion irradiation," Journal of Electronic Materials 45(4), 2258-2265. DOI: 10.1007/s11664-015-4293-4

Khan, W., Wang, Q., Jin, X., and Feng, T. (2017). "The effect of sputtering parameters and doping of copper on surface free energy and magnetic properties of iron and iron nitride nano thin films on polymer substrate," Materials 10(2), 217-237. DOI: $10.3390 / \mathrm{ma1} 0020217$

Kim, T. H., Lee, S. J., Kim, D. H., Dong, W. K., Bae, J. W., Kim, K. N., Yong, M. K., and Yeom, G. Y. (2018). "Residual stress control of $\mathrm{Cu}$ film deposited using a pulsed direct current magnetron sputtering," Thin Solid Films 660, 601-605. DOI: 10.1016/j.tsf.2018.05.011

Lan, Y., Li, X., Li, G., and Luo, Y. (2015). "Sol-gel method to prepare graphene/Fe ${ }_{2} \mathrm{O}_{3}$ aerogel and its catalytic application for the thermal decomposition of ammonium perchlorate," Journal of Nanoparticle Research 17(10), 395-404. DOI: 10.1007/s11051-015-3200-5

Lee, S.-H., Kang, D., and Oh, I.-K. (2017). "Multilayered graphene-carbon nanotube-iron oxide three-dimensional heterostructure for flexible electromagnetic interference shielding film," Carbon 111, 248-257. DOI: 10.1016/j.carbon.2016.10.003

Li, D., Seng, K. H., Shi, D., Chen, Z., Liu, H. K., and Guo, Z. (2013). “A unique sandwich-structured $\mathrm{C} / \mathrm{Ge} / g r a p h e n e$ nanocomposite as an anode material for high power lithium ion batteries," Journal of Materials Chemistry A 1(45), 14115-14121. DOI: $10.1039 / \mathrm{c} 3$ ta13324a

Li, N., Huang, Y., Du, F., He, X., Lin, X., Gao, H., Ma, Y., Li, F., Chen, Y., and Eklund, P. C. (2006). "Electromagnetic interference (EMI) shielding of single-walled carbon nanotube epoxy composites," Nano Letters 6(6), 1141-1145. DOI: $10.1021 / \mathrm{nl} 0602589$

Li, Q., Wang, Z.-L., Li, G.-R., Guo, R., Ding, L.-X., and Tong, Y.-X. (2012). “Design and synthesis of $\mathrm{MnO}_{2} / \mathrm{Mn} / \mathrm{MnO}_{2}$ sandwich-structured nanotube arrays with high supercapacitive performance for electrochemical energy storage," Nano Letters. 12(7), 3803-3807. DOI: 10.1021/nl301748m

Li, S.-S., Li, W.-J., Jiang, T.-J., Liu, Z.-G., Chen, X., Cong, H.-P., Liu, J.-H., Huang, Y.Y., Li, L.-N., and Huang, X.-J. (2016). "Iron oxide with different crystal phases $(\alpha-$ and $\gamma-\mathrm{Fe}_{2} \mathrm{O}_{3}$ ) in electroanalysis and ultrasensitive and selective detection of lead(II): An advancing approach using XPS and EXAFS," Analytical Chemistry 88(1), 906914. DOI: $10.1021 /$ acs.analchem.5b03570

Liu, A., Xu, T., Tang, J., Tang, W., Wu, H., and Zhao, T. (2014). "Sandwich-structured Ag/graphene/Au hybrid for surface-enhanced Raman scattering," Electrochimica Acta 119, 43-48. DOI: 10.1016/j.electacta.2013.12.036

Liu, F., Shan, C., Zhang, X., Zhang, Y., Zhang, W., and Pan, B. (2017). "Enhanced removal of EDTA-chelated $\mathrm{Cu}$ (II) by polymeric anion-exchanger supported nanoscale zero-valent iron," Journal of Hazardous Materials 321, 290-298. DOI: 10.1016/j.jhazmat.2016.09.022

Liu, G., Tian, Y., Zhang, B., Wang, L., and Zhang, X. (2019). "Catalytic combustion of VOC on sandwich-structured Pt@ZSM-5 nanosheets prepared by controllable intercalation," Journal of Hazardous Materials 367, 568-576. DOI: 10.1016/j.jhazmat.2019.01.014

Liu, J., Li, N., Goodman, M. D., Zhang, H .G., Epstein, E. S., Huang, B., Pan, Z., Kim, J., Choi, J. H., Huang, X., et al. (2015a). "Mechanically and chemically robust 
sandwich-structured C@Si@C nanotube array Li-ion battery anodes," ACS Nano 9(2), 1985-1994. DOI: 10.1021/nn507003z

Liu, J., Zhang, Y., Li, J., Li, J., Li, Y., Chen, Z., Feng, H., Jiang, J., and Qian, D. (2015b). "In situ chemical synthesis of sandwich-structured $\mathrm{MnO}_{2}$ /graphene nanoflowers and their supercapacitive behavior," Electrochimica Acta 173, 148-155. DOI: 10.1016/j.electacta.2015.05.040

Liu, Y., Gu, Y., Yan, X., Kang, Z., Lu, S., Sun, Y., and Zhang, Y. (2015c). “Design of sandwich-structured $\mathrm{ZnO} / \mathrm{ZnS} / \mathrm{Au}$ photoanode for enhanced efficiency of photoelectrochemical water splitting," Nano Research 8(9), 2891-2900. DOI: 10.1007/s12274-015-0794-y

Liu, Y., Zeng, J., Han, D., Wu, K., Yu, B., Chai, S., Chen, F., and Fu, Q. (2018). "Graphene enhanced flexible expanded graphite film with high electric, thermal conductivities and EMI shielding at low content," Carbon 133, 435-445. DOI: 10.1016/j.carbon.2018.03.047

Lv, P., Xu, W., Li, D., Feng, Q., Yao, Y., Pang, Z., Lucia, L. A., and Wei, Q. (2016). "Metal-based bacterial cellulose of sandwich nanomaterials for anti-oxidation electromagnetic interference shielding," Material \& Design 112, 374-382. DOI: 10.1016/j.matdes.2016.09.100

Meher, S. K., and Rao, G. R. (2013). "Archetypal sandwich-structured CuO for high performance non- enzymatic sensing of glucose," Nanoscale 5(5), 2089-2099. DOI: $10.1039 / \mathrm{c} 2 \mathrm{nr} 33264 \mathrm{~g}$

Meng, R., Hou, H., Liu, X., Yan, C., Duan, J., and Liu, S. (2016). "High performance binder-free quaternary composite $\mathrm{CuO} / \mathrm{Cu} / \mathrm{TiO}_{2} \mathrm{NT} / \mathrm{Ti}$ anode for lithium ion battery," Ceramics International 42(5), 6039-6045. DOI: 10.1016/j.ceramint.2015.12.160

Menon, A. V., Madras, G., and Bose, S. (2019). "Light weight, ultrathin, and "thermallyclickable" self-healing MWNT patch as electromagnetic interference suppressor," Chemical Engineering Journal 366, 72-82. DOI: 10.1016/j.cej.2019.02.086

Mohammed-Ziegler, I., Oszlánczi, Á., Somfai, B., Hórvölgyi, Z., Pászli, I., Holmgren, A., and Forsling, W. (2004). "Surface free energy of natural and surface-modified tropical and European wood species," Journal of Adhesion Science and Technology 18(6), 687-713. DOI: 10.1163/156856104839338

Mulinari, D. R., Voorwald, H .J., Cioffi, M. O., and Silva, M. L. D. (2016). “Cellulose fiber-reinforced high-density polyethylene composites - Mechanical and thermal properties," Journal of Composite Materials 51(13), 1807-1815. DOI: $10.1177 / 0021998316665241$

Munaweera, I., Aliev, A., and Balkus, K. J. (2014). "Electrospun cellulose acetate-garnet nanocomposite magnetic fibers for bioseparations," ACS Applied Materials \& Interfaces 6(1), 244-251. DOI: 10.1021/am404066g

Nourbakhsh, A., Abbaspour, S., Masood, M., Mirsattari, S. N., Vahedi, A., and Mackenzie, K. J. D. (2016). "Photocatalytic properties of mesoporous TiO2 nanocomposites modified with carbon nanotubes and copper," Ceramics International 42(10), 11901-11906. DOI: 10.1016/j.ceramint.2016.04.112

Pan, J., Yao, H., Li, X., Wang, B., Huo, P., Xu, W., Ou, H., and Yan, Y. (2011). "Synthesis of chitosan $/ \gamma-\mathrm{Fe}_{2} \mathrm{O}_{3} / \mathrm{fly}$-ash-cenospheres composites for the fast removal of bisphenol A and 2,4,6-trichlorophenol from aqueous solutions," Journal of Hazardous Materials 190(1-3), 276-284. DOI: 10.1016/j.jhazmat.2011.03.046 
Pang, S. C., Khoh, W. H., and Chin, S. F. (2010). "Nanoparticulate magnetite thin films as electrode materials for the fabrication of electrochemical capacitors," Journal of Materials Science 45(20), 5598-5604. DOI: 10.1007/s10853-010-4622-1

Piraman, S., Sundar, S., Mariappan, R., Kim, Y. Y., and Min, K. (2016). "Nanospheres and nanoleaves of $\gamma-\mathrm{Fe}_{2} \mathrm{O}_{3}$ architecturing for magnetic and biomolecule sensing applications," Sensors and Actuators B: Chemistry 234, 386-394. DOI: 10.1016/j.snb.2016.04.168

Qian, G., Chen, F., Zhang, J., Hong, G., Ni, J., Xiao, W., and Wang, D. (2009). “The study of novel $\mathrm{Fe}_{3} \mathrm{O}_{4} @ \gamma-\mathrm{Fe}_{2} \mathrm{O}_{3}$ core/shell nanomaterials with improved properties," Journal of Magnetism and Magnetic Materials 321(8), 1052-1057. DOI:

10.1016/j.jmmm.2008.10.022

Qiang, R., Du, Y., Zhao, H., Wang, Y., Tian, C., Li, Z., Han, X., and Xu, P. (2015). "Metal organic framework-derived Fe/C nanocubes toward efficient microwave absorption," Journal of Materials Chemistry A 3(25), 13426-13434. DOI: 10.1039/C5TA01457C

Ramandi, S., Entezari, M. H., and Ghows, N. (2017). "Sono-synthesis of novel magnetic nanocomposite $\left(\mathrm{Ba}-\alpha-\mathrm{Bi}_{2} \mathrm{O}_{3}-\gamma-\mathrm{Fe}_{2} \mathrm{O}_{3}\right)$ for the solar mineralization of amoxicillin in an aqueous solution," Physical Chemistry Research 5(2), 253-268. DOI: 10.22036/PCR.2017.40858

Rosa, M. F., Medeiros, E. S., Malmonge, J. A., Gregorski, K. S., Wood, D. F., Mattoso, L. H. C., Glenn, G., Orts, W. J., and Imam, S. H. (2010). "Cellulose nanowhiskers from coconut husk fibers: Effect of preparation conditions on their thermal and morphological behavior," Carbohydrate Polymers 81(1), 83-92. DOI: 10.1016/j.carbpol.2010.01.059

Shen, B., Li, Y., Zhai, W., and Zheng, W. (2016). "Compressible graphene-coated polymer foams with ultralow density for adjustable electromagnetic interference (EMI) shielding," ACS Applied Materials \& Interfaces 8(12), 8050-8057. DOI: 10.1021/acsami.5b11715

Shi, Z., Xing, L., Liu, Y., Gao, Y., and Liu, J. (2018). “A porous biomass-based sandwich-structured $\mathrm{Co}_{3} \mathrm{O}_{4} @$ Carbon Fiber@ $\mathrm{Co}_{3} \mathrm{O}_{4}$ composite for high-performance supercapacitors," Carbon 129, 819-825. DOI: 10.1016/j.carbon.2017.12.105

Song, J., Yu, Z., Xu, T., Chen, S., Sohn, H., Regula, M., and Wang, D. (2014a). "Flexible freestanding sandwich-structured sulfur cathode with superior performance for lithium-sulfur batteries," Journal of Materials Chemistry A 2(23), 8623-8627. DOI: 10.1039/C4TA00742E

Song, W.-L., Fan, L.-Z., Cao, M.-S., Lu, M.-M., Wang, C.-Y., Wang, J., Chen, T.-T., Li, Y., Hou, Z.-L., and Liu, J. et al. (2014b). "Facile fabrication of ultrathin graphene papers for effective electromagnetic shielding," Journal of Material Chemistry C 2(25), 5057-5064. DOI: 10.1039/C4TC00517A

Sonia, A., and Dasan, K. P. (2013). "Chemical, morphology and thermal evaluation of cellulose microfibers obtained from Hibiscus sabdariffa," Carbohydrate Polymers 92(1), 668-674. DOI: 10.1016/j.carbpol.2012.09.015

Sun, Y., Luo, S., Sun, H., Zeng, W., Ling, C., Chen, D., Chan, V., and Liao, K. (2018). "Engineering closed-cell structure in lightweight and flexible carbon foam composite for high-efficient electromagnetic interference shielding," Carbon 136, 299-308. DOI: 10.1016/j.carbon.2018.04.084

Thomassin, J.-M., Jérôme, C., Pardoen, T., Bailly, C., Huynen, I., and Detrembleur, C. (2013). "Polymer/carbon based composites as electromagnetic interference (EMI) 
shielding materials," Materials Science and Engineering: R: Reports 74(7), 211-232. DOI: 10.1016/j.mser.2013.06.001

Tian, B., Dong, R., Zhang, J., Bao, S., Yang, F., and Zhang, J. (2014). "Sandwichstructured $\mathrm{AgCl} @ \mathrm{Ag} @ \mathrm{TiO}_{2}$ with excellent visible-light photocatalytic activity for organic pollutant degradation and E. coli K12 inactivation," Applied Catalysis B: Environmental 158, 76-84. DOI: 10.1016/j.apcatb.2014.04.008

Tong, Z., Yang, Y., Wang, J., Zhao, J., Su, B.-L., and Li, Y. (2014). “Layered polyaniline/graphene film from sandwich-structured polyaniline/graphene/polyaniline nanosheets for high-performance pseudosupercapacitors," Journal of Materials Chemistry A 2(13), 4642-4651. DOI: 10.1039/C3TA14671E

Tzounis, L., Debnath, S., Rooj, S., Fischer, D., Mäder, E., Das, A., Stamm, M., and Heinrich, G. (2014). "High performance natural rubber composites with a hierarchical reinforcement structure of carbon nanotube modified natural fibers," Materials \& Design 58(6), 1-11. DOI: 10.1016/j.matdes.2014.01.071

Wan, C., and Li, J. (2016). "Graphene oxide/cellulose aerogels nanocomposite: Preparation, pyrolysis, and application for electromagnetic interference shielding," Carbohydrate Polymers 150, 172-179. DOI: 10.1016/j.carbpol.2016.05.051

Wang, L., Qiu, H., Liang, C., Song, P., Han, Y., Han, Y., Gu, J., Kong, J., Pan, D., and Guo, Z. (2019a). "Electromagnetic interference shielding MWCNT-

$\mathrm{Fe}_{3} \mathrm{O}_{4} @ \mathrm{Ag} /$ epoxy nanocomposites with satisfactory thermal conductivity and high thermal stability," Carbon 141, 506-514. DOI: 10.1016/j.carbon.2018.10.003

Wang, Q., Xiao, S., Shi, S. Q., and Cai, L. (2018). "Effect of light-delignification on mechanical, hydrophobic, and thermal properties of high-strength molded fiber materials," Scientific Reports 8(1), 955-964. DOI: 10.1038/s41598-018-19623-4

Wang, Q., Xiao, S., Shi, S. Q., Xu, S., and Cai, L. (2019b). "Self-bonded natural fiber product with high hydrophobic and EMI shielding performance via magnetron sputtering Cu film," Applied Surface Science 475, 947-952. DOI:

10.1016/j.apsusc.2019.01.059

Wang, Y., Cui, J., Wang, L., Yuan, Q., Niu, Y., Chen, J., Wang, Q., and Wang, H. (2017). "Compositional tailoring effect on electric field distribution for significantly enhanced breakdown strength and restrained conductive loss in sandwich-structured ceramic/polymer nanocomposites," Journal of Materials Chemistry A 5(9), 47104718. DOI: 10.1039/C6TA10709E

Wiatrowski, A., Posadowski, W. M., Jóźwiak, G., Serafińczuk, J., Szeloch, R., and Gotszalk, T. (2011). "Standard and self-sustained magnetron sputtering deposited $\mathrm{Cu}$ films investigated by means of AFM and XRD," Microelectronics Reliability 51(7), 1203-1206. DOI: 10.1016/j.microrel.2011.02.024

Wu, B., Haehnlein, I., Shchelkanov, I., Mclain, J., Patel, D., Uhlig, J., Jurczyk, B., Leng, Y., and Ruzic, D. N. (2018). "Cu films prepared by bipolar pulsed high power impulse magnetron sputtering," Vacuum 150, 216-221. DOI: 10.1016/j.vacuum.2018.01.011

Wu, H., and Wang, L. (2014). "Phase transformation-induced crystal plane effect of iron oxide micropine dendrites on gaseous toluene photocatalytic oxidation," Applied Surface Science 288(1), 398-404. DOI: 10.1016/j.apsusc.2013.10.046

Wu, Q. X., Zhao, T. S., Chen, R., and An, L. (2013). "A sandwich structured membrane for direct methanol fuel cells operating with neat methanol," Applied Energy 106, 301-306. DOI: 10.1016/j.apenergy.2013.01.016 
Xia, C., Ren, H., Shi, S. Q., Zhang, H., Cheng, J., Cai, L., Chen, K., and Tan, H.-S. (2016a). "Natural fiber composites with EMI shielding function fabricated using VARTM and Cu film magnetron sputtering," Applied Surface Science 362(5), 335340. DOI: 10.1016/j.apsusc.2015.11.202

Xia, C., Wang, K., Dong, Y., Zhang, S., Shi, S. Q., Cai, L., Ren, H., Zhang, H., and Li, J. (2016b). "Dual-functional natural-fiber reinforced composites by incorporating magnetite," Composites Part B: Engineering 93(221), 221-228. DOI: 10.1016/j.compositesb.2016.03.016

Xia, C., Zhang, S., Ren, H., Shi, S. Q., Zhang, H., Cai, L., and Li, J. (2015). "Scalable fabrication of natural-fiber reinforced composites with electromagnetic interference shielding properties by incorporating powdered activated carbon," Materials 9(1), 1019. DOI: $10.3390 / \mathrm{ma9010010}$

Yang, L., Ma, Q., Xi, X., Li, D., Liu, J., Dong, X., Yu, W., Wang, J., and Liu, G. (2019). "Novel sandwich-structured composite pellicle displays high and tuned electrically conductive anisotropy, magnetism and photoluminescence," Chemical Engineering Journal 361, 713-724. DOI: 10.1016/j.cej.2018.12.125

Zhai, Y., Wang, N., Mao, X., Si, Y., Yu, J., Al-Deyab, S. S., El-Newehy, M., and Ding, B. (2014). "Sandwich-structured PVdF/PMIA/PVdF nanofibrous separators with robust mechanical strength and thermal stability for lithium ion batteries," Journal of Materials Chemistry A 2(35), 14511-14518. DOI: 10.1039/C4TA02151G

Zhang, W., Liang, F., Li, C., Qiu, L.-G., Yuan, Y.-P., Peng, F.-M., Jiang, X., Xie, A.-J., Shen, Y.-H., and Zhu, J.-F. (2011). "Microwave-enhanced synthesis of magnetic porous covalent triazine-based framework composites for fast separation of organic dye from aqueous solution," Journal of Hazardous Materials 186(2-3), 984-990. DOI: 10.1016/j.jhazmat.2010.11.093

Zhang, Y., Xu, S., Li, X., Zhang, J., Sun, J., Tong, L., Zhong, H., Xia, H., Hua, R., and Chen, B. (2018). "Improved LRET-based detection characters of $\mathrm{Cu}^{2+}$ using sandwich structured $\mathrm{NaYF}_{4} @ \mathrm{NaYF}_{4}: \mathrm{Er}^{3+} / \mathrm{Yb}^{3+} @ \mathrm{NaYF}_{4}$ nanoparticles as energy donor," Sensors and Actuators B: Chemical 257, 829-838. DOI: 10.1016/j.snb.2017.11.045

Zhao, H., Hou, L., and Lu, Y. (2016). "Electromagnetic shielding effectiveness and serviceability of the multilayer structured cuprammonium fabric/polypyrrole/copper (CF/PPy/Cu) composite," Chemical Engineering Journal 297, 170-179. DOI: 10.1016/j.cej.2016.04.004

Zhao, L., Gao, M., Yue, W., Jiang, Y., Wang, Y., Ren, Y., and Hu, F. (2015). "Sandwichstructured graphene-Fe $\mathrm{F}_{4} @$ carbon nanocomposites for high-performance lithiumion batteries," ACS Applied Materials \& Interfaces 7(18), 9709-9715. DOI: 10.1021/acsami.5b01503

Zhu, X., Dong, H., and Lu, K. (2008). "Coating different thickness nickel-boron nanolayers onto boron carbide particles," Surface and Coating Technology 202(13), 2927-2934. DOI: 10.1016/j.surfcoat.2007.10.021

Article submitted: May 27, 2020; Peer review completed: September 5, 2020; Revised version received: September 9, 2020; Accepted: September 11, 2020; Published:

September 18, 2020.

DOI: $10.15376 /$ biores.15.4.8384-8402 